\title{
Flame extinction and burning behaviour of timber under varied oxygen concentrations
}

\author{
Juan Cuevas $^{\mathrm{a}^{*}}$, Jose Luis Torero ${ }^{\mathrm{b}}$, and Cristian Maluk ${ }^{\mathrm{a}}$
}

${ }^{a}$ School of Civil Engineering, The University of Queensland, Brisbane, Australia, j.cuevas@uq.edu.au,c.maluk@uq.edu.au

${ }^{\mathrm{b}}$ Dept. of Civil, Environ \&Geomatic Engineering, Faculty of Engineering Science, University College London, London, UK, j.torero@ucl.ac.uk

* Corresponding author

\section{Highlights:}

- At $21 \% \mathrm{O}_{2}$, the maximum incident heat flux for extinction is $30 \mathrm{~kW} / \mathrm{m}^{2}$

- At $21 \% \mathrm{O}_{2}$, the minimum incident heat flux to ensure sustained flaming is $40 \mathrm{~kW} / \mathrm{m}^{2}$

- Critical heat fluxes for extinction is higher at lower oxygen concentrations

- At $21 \% \mathrm{O}_{2}$, the MLR during self-extinction is $3.65 \pm 0.4 \mathrm{~g} / \mathrm{m}^{2} \mathrm{~s}$

- Critical MLR at extinction is lower for lower oxygen concentrations

\begin{abstract}
:
Self-extinction plays a key role in enabling the safe use of timber structures in mid- and high-rise construction, where structural integrity during and after a fire is key. To date, the influence that oxygen concentration may have in the conditions that lead to self-extinction has not been studied in depth. Also, the thermal conditions of timber after self-extinction has occurred have also not been carefully studied. During fires, oxygen concentrations will defer from those during ambient conditions. Within this study, the testing conditions were carefully controlled to investigate the circumstances before and after the occurrence of self-extinction; considering a range of heat exposures and oxygen concentrations in the air surrounding the test sample. A statistically sound number of repeat tests was done to estimate the occurrence of self-extinction. For samples tested in air containing $21 \%$ oxygen, self-extinction always occurs for an incident heat flux of $30 \mathrm{~kW} / \mathrm{m}^{2}$ but never occurs for $40 \mathrm{~kW} / \mathrm{m}^{2}$; with the critical mass loss rate that leads to self-extinction being $3.65 \pm 0.4 \mathrm{~g} / \mathrm{m}^{2} \mathrm{~s}$. The study concluded that lower oxygen concentrations result in an increase of the critical mass loss rate leading to self-extinction and an increase of the minimum incident heat flux leading self-extinction.
\end{abstract}

Keywords: Timber, self-extinction, oxygen concentration, mass loss rate, external incident heat flux, fire. 


\section{Introduction and background}

Due to the continuous densification of modern cities, mid-rise construction is experiencing a rapid growth within the construction industry worldwide. Engineered Timber Products (ETPs) like Cross-laminated Timber (CLT) are placed as the preferred alternative for mid-rise construction. Furthermore, driven mainly by the aesthetical appeal and ease of construction, there is a growing demand for load-bearing timber structures to remain exposed.

Unfortunately, due to its combustible nature, exposed timber (i.e. not protected with nonflammable materials) presents a new challenge that must be addressed before structural timber can be used with the same confidence as other building materials and systems. In the event of a fire, exposed timber inside of a compartment will contribute to the fire growth, intensity, duration, and eventual decay of the fire [1]. In order to ensure structural integrity, achieving the cease of flaming combustion after burnout of the original fuel load within the compartment is critical.

Furthermore, during a compartment fire the burning elements may be exposed to under-ventilated atmospheres with oxygen $\left(\mathrm{O}_{2}\right)$ concentrations that can go as low as $0 \%$ [2,3] as a consequence of the recirculation of combustion products [4]. This variation of the atmosphere will influence the ongoing thermal decomposition of the burning elements [2] and it should be considered as a parameter when studying the conditions that lead to the self-extinction of timber.

\subsection{Self-extinction of timber}

The occurrence of self-extinction of timber has been reported by several researchers in the past, mainly as an event observed in studies focused in understanding the different phenomena related to the burning of timber [5-7]. Nevertheless, the growing need to design fire-safe timber structures has increased interest in this phenomenon.

Emberley et al. [8] reported that the occurrence of self-extinction (defined by the author as flame extinction) is always attained for samples made of 6 different species ( 2 types of CLT, and 4 types of solid timber) after completely halting the external source of heat. In this work, the time to selfextinction varied because of heat-induced delamination of the lamellae of the CLT samples. When self-extinction occurred, a critical mass loss rate of approximately $4.0 \mathrm{~g} / \mathrm{m}^{2} \mathrm{~s}$ was measured. Following work of the same author determined that a critical amount of approximately $44 \mathrm{~kW} / \mathrm{m}^{2}$ must be provided in order to sustain flaming combustion [9] for CLT Radiata Pine samples.

Crielaard et al. [10] performed similar bench-scale CLT experiments and determined the critical incident heat flux for self-extinction to be between 5 and $6 \mathrm{~kW} / \mathrm{m}^{2}$; self-extinction being defined as the termination of any type of combustion process (including smouldering).

Bartlett et al. [11] tested bench-scale European Spruce CLT samples under similar conditions and concluded that the conditions for self-extinction (also defined here as flame extinction) may occur for an incident heat flux of $32 \mathrm{~kW} / \mathrm{m}^{2}$ and a mass loss rate of $3.5 \mathrm{~g} / \mathrm{m}^{2} \mathrm{~s}$. 


\subsection{The effect of oxygen}

The influence of $\mathrm{O}_{2}$ concentrations in the atmosphere surrounding the burning surfaces of timber is a subject that is well within the heart of timber combustion research, and it is pertinent not only to fire research, but also for the use of timber as a fuel [12].

It has been found that reducing the $\mathrm{O}_{2}$ concentration in the atmosphere increases the time to ignition [4,12]. Moreover, if ignition is achieved, a decrease in ambient $\mathrm{O}_{2}$ concentration will reduce the flame temperature [13]. An immediate effect of this is a decrease in the thermal feedback from the flame to the solid's surface. Furthermore, if the flame temperature drops to the $1500 \mathrm{~K}$ range, extinction is likely to occur [14].

Several researchers have reported a decrease in the sample's mass loss rate (MLR) when tested under atmospheres with lower $\mathrm{O}_{2}$ concentrations [15]. In general terms, it has been found that a reduction in the $\mathrm{O}_{2}$ concentration will lower the rates of char oxidation $[16,17]$ and pyrolysis $[4,12]$ in burning timber; oxygen concentration having a high influence in char oxidation and a smaller one in the pyrolysis front. As a consequence of the above, the thickness of the char layer will increase for low $\mathrm{O}_{2}$ concentrations [12]. This causes that less of the heat at the surface of the burning solid is transferred to the pyrolysis front, decreasing the charring rate; this last will inevitably influence the conditions that lead to the occurrence of self-extinction of timber.

\subsection{Aim of the study}

Despite the abundant work focused on studying the burning behaviour of timber, there is a lack of understanding on the influence of $\mathrm{O}_{2}$ concentration in the varied stages of burning; from ignition to extinction. The aim of the work described herein is to generate between the occurrence of selfextinction and all prior stages of the burning behaviour that lead to that critical condition. And also, to investigate the influence that $\mathrm{O}_{2}$ concentrations near the burning surfaces of timber has in the occurrence of self-extinction.

\section{Theoretical background}

\subsection{Burning behaviour}

When exposed to heat, timber undergoes different thermal and chemical processes, which will be triggered under different energetic levels (temperature) [18]. The first one of these processes is the evaporation of moisture contained within the material, that will produce a pressure build-up that promotes the diffusion of water in and out of the material.

As the temperature rise continues, there is an onset for the decomposition (pyrolysis) of the natural polymers; at an early stage, mostly water vapour, carbon dioxide, carbon monoxide, and some non-combustible volatiles are released [18]. At a later stage, there is an increase in the reaction rate due to the increase in temperature, the gaseous products become volatile, and ignition conditions are reached at the surface, enabling the onset of flaming combustion. As the reaction front progresses, it leaves behind a carbon-rich solid, char. Char is not completely inert, but as a lower thermal conductivity than the original material and therefore acts as an insulator between the external heat acting on the surface of the material, and the progressing pyrolysis front [18]. 
At higher temperatures, char oxidation occurs. This exothermic reaction provides additional heat into the solid, reduces the thickness of the char layer, and consequently increases the distance between the burning solid, and the heat source. As a consequence, the amount of energy that reaches the pyrolysis front decreases, reducing the rate of generation of combustible gases. If the flow rate of combustible gases diffusing out of the solid is below a critical threshold, flame extinction will take place.

\subsection{Flame extinction in timber}

The process described above can be characterized through the following energy balance at the char layer (Figure 1(a)). A more detailed description of this balance is provided in [9].
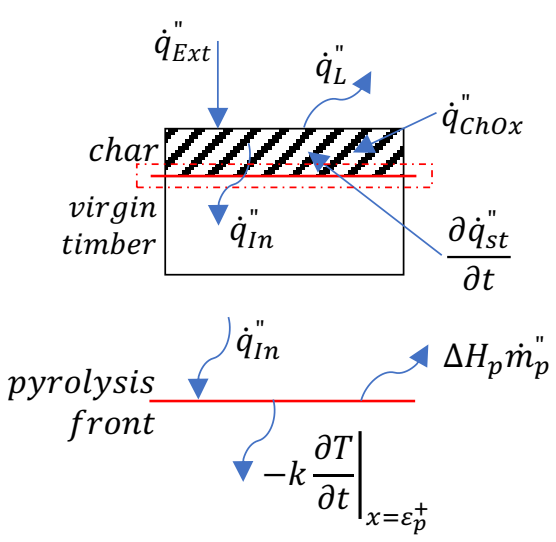

(a)

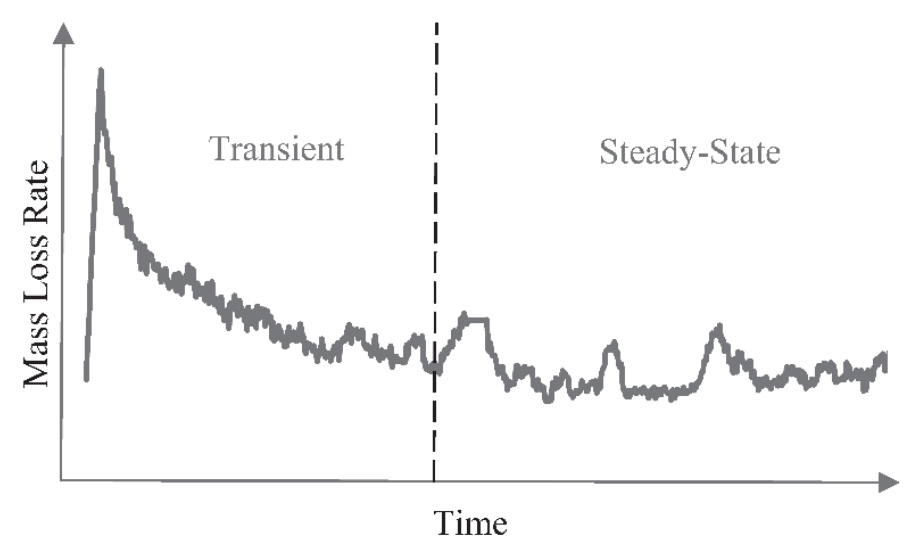

(b)

Figure 1: Burning of timber. (a) Energy balance at the char layer. (b) MLR of a burning timber element. Source [9].

$\frac{\partial \dot{q}_{s t}^{\prime \prime}}{\partial t}=\rho_{\text {char }} c_{p \text { char }} \frac{\partial T}{\partial t}=\dot{q}_{E x t}^{\prime \prime}+\dot{q}_{C h O x}^{\prime}-\dot{q}_{I n}^{\prime \prime}-\dot{q}_{L}^{\prime \prime}$

Where $\dot{q}_{\text {Ext }}^{\prime \prime}$ is the net incident heat flux over the exposed surface (per unit of area) of the burning material, incorporating both the radiation from the flame back to the surface, in addition to any other external source of heat imposed over the surface of the material. Following, $\dot{q}_{\text {Chox }}^{\prime \prime}$ is the heat flux generated from the exothermic oxidation of char, $\dot{q}_{I n}^{\prime \prime}$ is the heat flux conducted inwards through the char layer and $\dot{q}_{L}^{\prime \prime}$ represents the heat losses occurring at the solid's exposed surface.

Following, as heat is conducted through the char layer, it reaches the pyrolysis front, where the following balance can be established,

$\Delta H_{p} \dot{m}_{p}^{\prime \prime}=\dot{q}_{I n}^{\prime \prime}-\left(-\left.k \frac{\partial T}{\partial x}\right|_{x=\varepsilon_{p}^{+}}\right)$

Where $\Delta H_{p}$ is the heat of pyrolysis of timber, $\dot{m}_{p}^{\prime \prime}$ is the mass flow (per unit of area) of pyrolysis gases being generated, and the last term on the right describes the unused energy that is conducted into the virgin material, propagating the thermal wave within it. 
By combining Eqs. (1) and (2), and solving for $\dot{m}_{p}^{\prime \prime}$, the following expression is obtained:

$\dot{m}_{p}^{\prime \prime}=\frac{1}{\Delta H_{p}}\left[\dot{q}_{E x t}^{\prime \prime}+\dot{q}_{C h O x}^{\prime \prime}-\dot{q}_{L}^{\prime \prime}-\left(-\left.k \frac{\partial T}{\partial x}\right|_{x=\varepsilon_{p}^{+}}\right)-\rho_{c h a r} c_{p \operatorname{char}} \frac{\partial T}{\partial t}\right]$

This expression describes the mass flow of pyrolysis gases, and consequently the solid's mass loss rate [8].

By inspecting the last expression, it can be seen that $\dot{m}_{p}^{\prime \prime}$ is at its maximum when the flow of unused energy that leaves the pyrolysis front is minimal, and no energy is spent in heating up the char layer. This last part can be translated as the char layer reaching a thermal steady-state.

The arrival to a steady-state within the burning timber, as described by Emberley [9], is a twostage process (Fig. 1(b)). Right after ignition, a transient stage characterized by the occurrence of a peak mass loss rate begins. This peak is due to the presence of a relatively thin (but growing) char layer that can only retain a small fraction of the heat that reaches the exposed surface, and allows that the rest of it is transferred into the pyrolysis front.

As the depth of the char layer increases, its capacity to store heat increases as well; hence, the amount of heat that reaches the pyrolysis front diminishes, lowering the mass flow of pyrolysis gases being generated. This decrease in mass flow has been found to follow a $t^{-1 / 2}$ relationship [19]. After a certain time and considering the ongoing char oxidation process at the burning surface, as well as the rest of the phenomena happening at the burning surface, a thermal steadystate, characterized by a constant-thickness char layer, is reached.

At this stage, flaming combustion may be sustained. If the mass flow of pyrolysis gases being generated drops below a critical value, flame extinction will occur. Based on this analysis, the selfextinction of timber can be studied in terms of a worst-case-scenario analysis; if critical conditions that lead to flame extinction are identified when the mass flow of pyrolysis gases being generated is constant, then these conditions will induce flame extinction for every other scenario that is less severe as well.

\section{Methodology}

In the following section, the experimental setup, testing conditions, and the experimental methodology used in this work are presented.

\subsection{Experimental setup}

The experiments described herein were conducted using FM-Global's Fire Propagation Apparatus (FPA) [20]. From the global schematic presented in Figure 2, two main components of the apparatus will be thoroughly described herein; the combustion chamber and the exhaust system. 


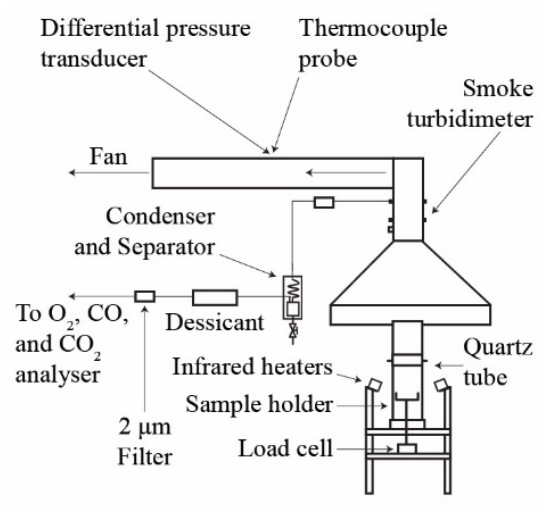

Figure 2: Schematic of the FPA.

\section{Description of the combustion chamber section}

Whiting the combustion chamber, the sample sits over a sample holder that is directly connected to a load cell (Tedea Huntleigh model no. 505H-0002-F070, \pm 3 g accuracy, $1 \mathrm{~Hz}$ sampling rate) that registers the evolution of the sample's mass during the experiment.

A set of three mass flow controllers (Bronkhorst F-203AV, $\pm 0.6 \%$ accuracy) regulating the flows of air, $\mathrm{O}_{2}$, and $\mathrm{N}_{2}$, and a posterior gas mixing chamber are used to control the oxidizer composition which the samples are tested. The oxidizer flow is finally supplied into the testing section by means of a distribution chamber placed at the bottom of the combustion chamber. In order to confine the atmosphere under which the samples are tested, a two-section (162 mm ID) quartz tube is used.

The sample is heated by means of a set of four infrared heaters (Research Inc. model no. 520905). These heaters correspond to an array of six halogen tubular quartz lamps that allow imposing heat fluxes within the range of $0-100 \mathrm{~kW} / \mathrm{m}^{2}$ over the sample (depending on their orientation). Before every test, the heat flux provided by the lamps is calibrated by means of a Schmidt-Boeltertype heat flux gage (Medtherm model no. GTW-10SB-8-36-40-484, $\pm 3 \%$ accuracy). A premixed ethylene/air jet pilot flame is used to trigger flaming combustion. This pilot flame is $1 \mathrm{~cm}$ long (visible length), and located $1 \mathrm{~cm}$ above the sample, as described in [20].

Due to the spectral dependency of quartz's transmissivity [21,22], its presence must be considered when calibrating the incident heat flux over the sample. Moreover, to measure the thermal response of the sample, type $\mathrm{K}$ thermocouples embedded within the sample were used.

\section{Description of the exhaust system}

The combustion-generated products are collected and transported through the upper section of the apparatus; the exhaust system. The exhaust system is composed by an intake hood, a test section, and a high-temperature blower that evacuates the gases at a constant flow of $150 \mathrm{slpm}$. A gas sampling device [20] is used to collect gas samples that are passed through a condenser-desiccant stage. After this, a gas analyser (Servomex SERVOPRO 4100) is used to measure the concentration of $\mathrm{O}_{2}$, and $\mathrm{CO} / \mathrm{CO}_{2}$ of the sample gases (additionally to the $\mathrm{O}_{2}$ concentration in the 
oxidizer is supplied to the combustion chamber). Downstream from the gas sampler, a laser extinction diagnostic is used to evaluate soot production.

\subsection{Experimental approach}

Based on the works of Emberley et al. [8], and Bartlett et al. [11], in order to determine both the critical mass loss rate and the critical incident heat flux that lead to flame extinction, the samples were subjected to two-stage test.

First, in order to achieve the worst-case-scenario situation proposed in the theoretical background section, samples were exposed to a heat flux of $50 \mathrm{~kW} / \mathrm{m}^{2}$ until a thermal steady-state was reached. For all of the $\mathrm{O}_{2}$ concentrations used and under the same incident heat flux, an exposure time of 20 minutes was found to be sufficient to reach the desired thermal condition within the solid.

Once steady-state is reached, the incident heat flux is decreased (not removed) to determine the minimum additional heat flux to be provided in order to sustain flaming. If flame extinction occurred, the time of occurrence was registered to subsequently determine the sample's mass loss rate and incident heat flux at the moment of extinction, the latter one being corrected by the displacement (regression) of the exposed surface of the sample due to char oxidation.

Finally, in order to obtain ensure repeatability and good quality in the results, a series of measures were adopted; Firstly, it was found that the presence of the natural (knots) and fabrication defects (finger joints) at the exposed surface affects the thermal response of the sample especially during the early stages of the test (results not reported here). Furthermore, this effect increases as the sample cross-section decreases. To overcome this, all of the samples used for this study were selected to have no visible defects in the first lamella. Secondly, due to the intrinsically inhomogeneous nature of timber [23], 6 repetitions were performed for each condition tested. Thus, the work presented herein is the result of a total of 144 experiments conducted through the different experimental campaigns.

\subsection{Conditions studied and sample preparation}

\section{Experimental conditions}

Within the scope of the experiments described herein, the following conditions were studied: (1) the $\mathrm{O}_{2}$ concentration under which the samples are tested, and (2) the external incident heat flux over the sample.

As previously mentioned, three mass flow controllers are used to define the atmosphere under which the samples are tested. Table 1 shows the $\mathrm{O}_{2}$ concentration studied in the present work.

Table 1: Atmosphere compositions used in the experiments.

\begin{tabular}{llll}
\hline $\mathrm{O}_{2}$ content $(\%)$ & Air flow $(\mathrm{slpm})$ & $\mathrm{N}_{2}$ flow $(\mathrm{slpm})$ & Total oxidizer flow $(\mathrm{slpm})$ \\
\hline 21 & 200 & -- & 200.0 \\
19 & 181.5 & 18.8 & 200.3 \\
17 & 162.5 & 37.6 & 200.1 \\
\hline
\end{tabular}


As it can be seen, an oxidizer flow of 200 slpm was maintained throughout the tests. Given the available path for the oxidizer to flow through (cross-section of the combustion chamber minus the footprint of the sample), this volumetric flow translates into a linear speed of $0.32 \mathrm{~m} / \mathrm{s}$.

As previously discussed, external radiant heat fluxes that ranged from 30 to $50 \mathrm{~kW} / \mathrm{m}^{2}$ were used. For all the experiments conducted, the incident heat flux provided by the heaters over any given point in the target surface was found to deviate no more than 5\% from the mean (Fig. 3(a)).

Moreover, the spatial distribution of the radiant incident heat flux over the complete sample was evaluated by means of a numerical model based on theoretical calculations [24]. The results of this model (Figs. 3(a) and 3(b)) show the presence of an originally unaccounted heat flux over the lateral faces of the sample. Roughly, this lateral incident heat flux was found to be approximately $40 \%$ (on average) of the maximum value found over the target (top) surface. This side-effect was addressed by insulating the sample (discussed in the following section).

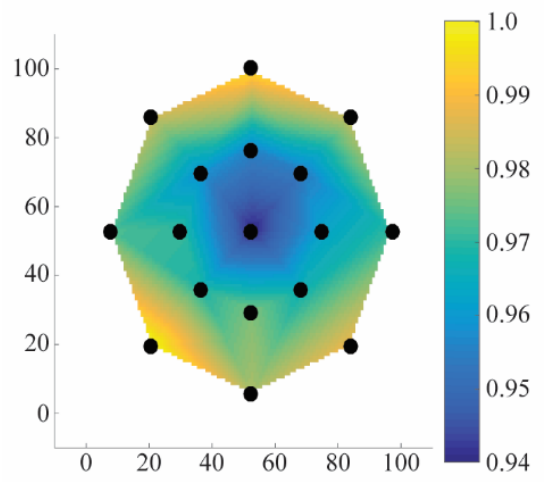

(a)

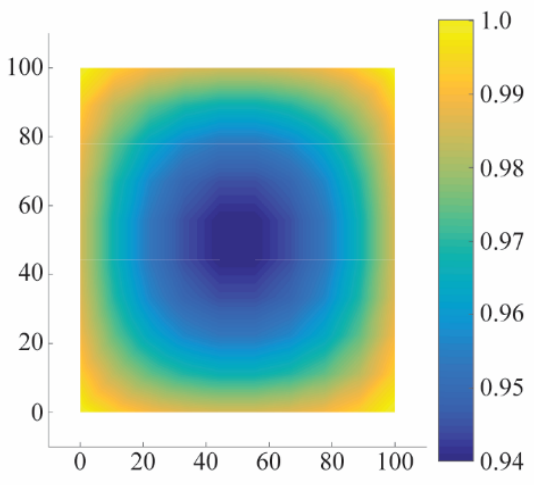

(b)

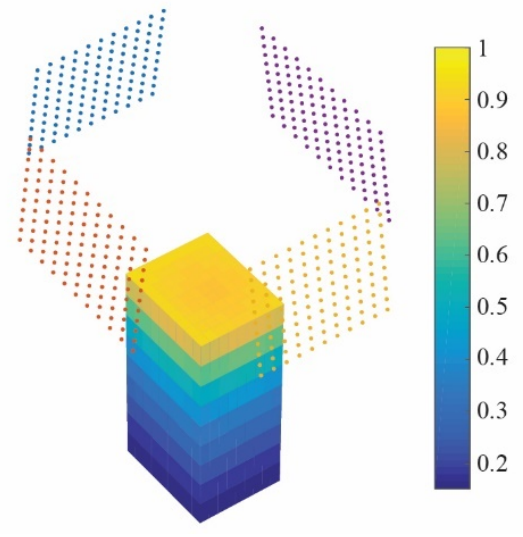

(c)

Figure 3: Incident heat flux over the target surface (normalized against the maximum value at the surface): (a) experimental results used as model validation, (b) modelled spatial distribution over the exposed surface, and (c) modelled spatial distribution over the complete sample.

\section{Sample preparation}

In the present study, bench-scale samples of commercially available five-ply Radiata Pine CLT $(45 / 20 / 20 / 20 / 45 \mathrm{~mm})$ were used. The samples prepared for these experiments had an exposed cross-section of $90 \times 90 \mathrm{~mm}^{2}$, and a thickness of $150 \mathrm{~mm}$. The samples had an average moisture content of $11 \%$ (by mass) and an average density of $637 \mathrm{~kg} / \mathrm{m}^{3}$.

The sample dimensions have been determined in order to sustain a semi-infinite solid behaviour for the duration of the experiment. Moreover, the thickness and material of the insulation placed around the sample have been selected to minimize two-dimensional thermal effects generated by the additional lateral heating already described. A detailed explanation of this can be found in [25].

The samples were instrumented with 13 shielded thermocouples (Type-K - $1.5 \mathrm{~mm}$ diameter), placed at 3, 7 (x2), 12(x2), 22(x2), 32(x2), 42, 52, 62, 72, and $150 \mathrm{~mm}$ from the exposed surface. 
The sides of each test sample were covered with one $9 \mathrm{~mm}$ layer of Ceramic Paper $\left(\mathrm{SiO}_{2}-\mathrm{Al}_{2} \mathrm{O}_{3}\right.$ based material) and one outer layer of commercially available aluminium foil.

\section{Results}

To properly understand the occurrence of flame extinction, the prior history to its occurrence must be also considered. Subsequently, this section is structured as follows; Firstly, the initial burning of timber will be studied. Secondly, the extinction of timber under different testing conditions will be discussed. Finally, different scenarios found after the decrease of the incident heat flux over the sample will be presented.

\subsection{Burning behaviour}

Error! Reference source not found. shows the transient evolution of the sample's mass loss rate (MLR) and time to ignition for the different atmospheres studied, and under a constant thermal exposure of $50 \mathrm{~kW} / \mathrm{m}^{2}$. Firstly, it was found that the ignition delay time is greatly affected by the $\mathrm{O}_{2}$ concentration present in the atmosphere. Under a $21 \% \mathrm{O}_{2}$ atmosphere, the average time to ignition was found to be of approximately $52 \pm 2$ seconds (average taken from 48 test samples). When decreasing the $\mathrm{O}_{2}$ concentration, this parameter was found to increase to $65 \pm 3$ and $82 \pm 5$ seconds under atmospheres containing $19 \%$ and $17 \% \mathrm{O}_{2}$ respectively. This can be explained by the decrease in $\mathrm{O}_{2}$ availability, that directly impacts the conditions of an oxygen/fuel ratio above the solid's surface that enables sustained flaming ignition. The apparent contradiction between this finding and the results presented by Delichatsios et al. [4] can be partially justified by the significant difference in the spectral emissivity of the heating elements used [26], and how the exposed timber surface will respond [27]. This, combined by the delay in the charring of the exposed surface when the $\mathrm{O}_{2}$ available is reduced [12] will decrease the amount of energy that is effectively absorbed by the material before ignition conditions are achieved.

The transient stage prior to the arrival to the thermal steady-state can be described by inspecting the sample's MLR. In general terms, the behaviour showed is similar for all the $\mathrm{O}_{2}$ concentrations tested; after ignition, there is a rapid increase in the MLR and a following drop in magnitude due to the formation of char at the exposed surface. After a certain amount of time, the thermal condition within the sample reaches what could be described as a steady state, characterized by a somewhat constant MLR, and a $\partial M L R / \partial t$ that tends to zero. 


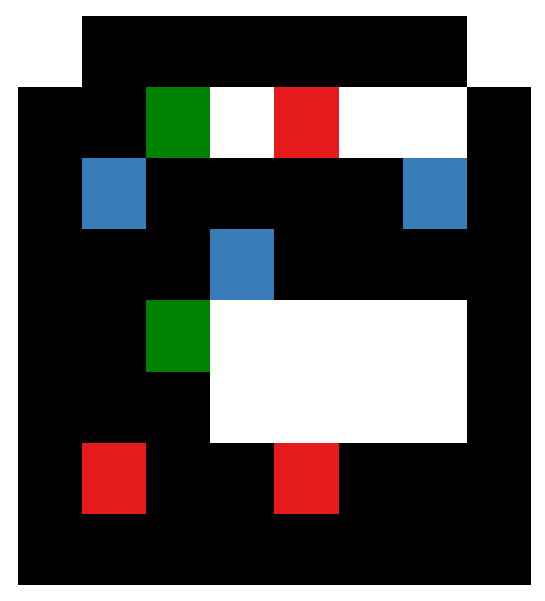

(a)

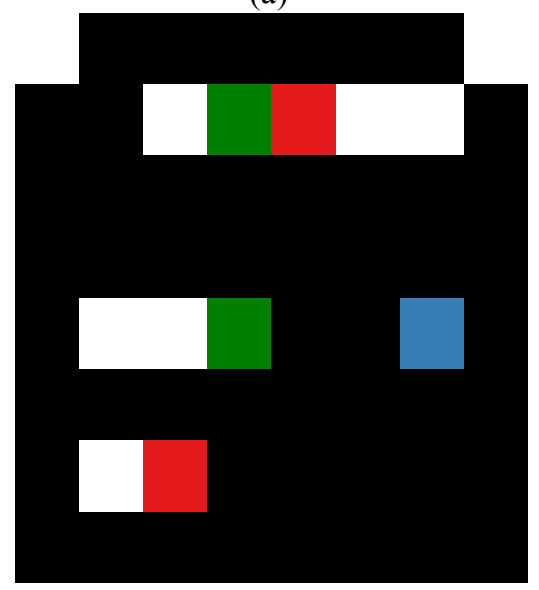

(c)

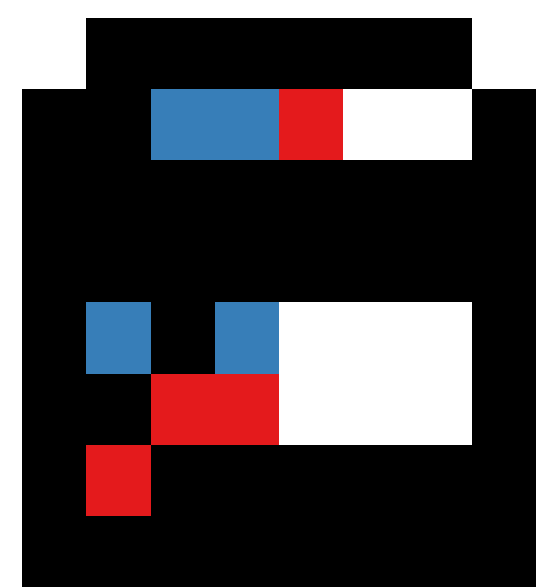

(b)

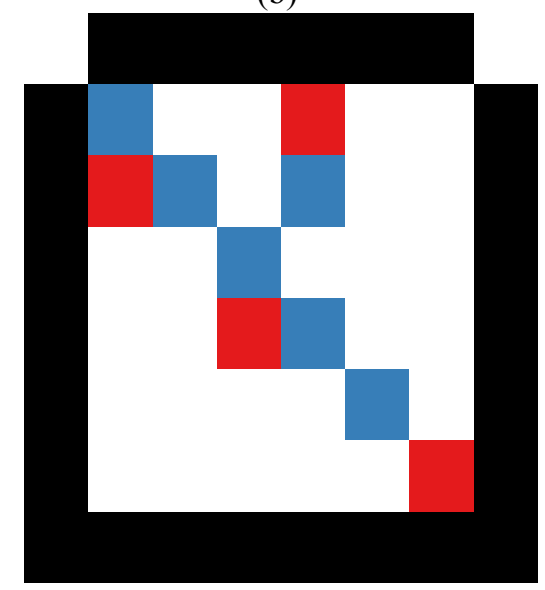

(d)

Figure 4: Transient burning of timber. (a) Average MLR at 17\% O2. (b) Average MLR at 19\% O2. (c) Average MLR at $21 \% \mathrm{O}_{2}$. (d) Time to ignition as a function of $\mathrm{O}_{2}$ concentration.

Furthermore, the time required to reach this thermal steady-state has a weak dependence on the $\mathrm{O}_{2}$ concentration tested. For the samples tested at $17 \% \mathrm{O}_{2}, \partial M L R / \partial t$ reaches a value sufficiently small after approximately 20 minutes. Moreover, this condition is reached after approximately 22.5 and 25 minutes when the oxygen concentration is increased to $19 \%$ and $21 \%$, respectively.

Despite of the already described weak influence of the $\mathrm{O}_{2}$ concentration over the time to reach a steady-state, in order to properly analyse behaviour showed by the samples under the different testing conditions, the following normalization is introduced

$\tau=\frac{t-t_{i g n}}{t_{s s}-t_{i g n}}$

Where $t_{i g n}$ is the time to ignition, and $t_{s s}$ is the time required to reach a steady-state.

Figure 5 shows the result of applying this normalization to the MLR, and to the propagation of the different reaction fronts within the sample. From Figure 5(a), the general behaviour of the MLR 
curves previously described becomes clearer as they collapse as a result of the normalization. From this, it is possible to identify a direct dependency between the magnitude of the MLR at any given time, and $\mathrm{O}_{2}$ concentration. This trend is present throughout the duration of this transient stage, and it becomes more evident when comparing the steady-state MLR that the samples reach under the different testing atmospheres. At ambient air conditions, the sample's MLR was found to reach a steady-state value of $5.09 \pm 0.5 \mathrm{~g} / \mathrm{m}^{2} \mathrm{~s}$, whereas values of $4.40 \pm 0.4 \mathrm{~g} / \mathrm{m}^{2} \mathrm{~s}$ and $3.91 \pm 0.6 \mathrm{~g} / \mathrm{m}^{2} \mathrm{~s}$ are obtained when the $\mathrm{O}_{2}$ concentration is decreased to $19 \%$ and $17 \%$, respectively.

Figure 5(b) presents the propagation of the different reactions that are taking place within the solid. In the present work, moisture migration within the sample was evaluated by tracking the $100^{\circ} \mathrm{C}$ isotherm. Similarly, the pyrolysis and char oxidation fronts were identified by tracking the $300^{\circ} \mathrm{C}$, and $500^{\circ} \mathrm{C}$ isotherms, respectively. From the figure, it can be seen that moisture migration is practically unaffected by changes in $\mathrm{O}_{2}$ concentration, reaching depths of approximately $32 \mathrm{~mm}$ on average for $\tau=1$. On the other hand, it can be seen that the propagation of both pyrolysis and char oxidation is affected by the concentration of $\mathrm{O}_{2}$. In both cases, the propagation depth decreases when the $\mathrm{O}_{2}$ concentration does.

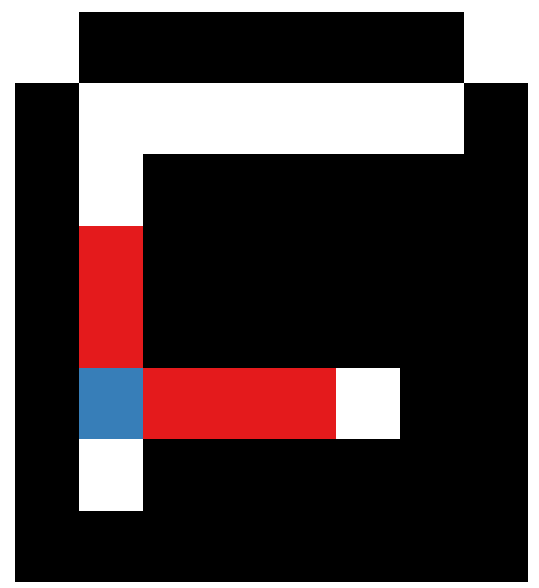

(a)

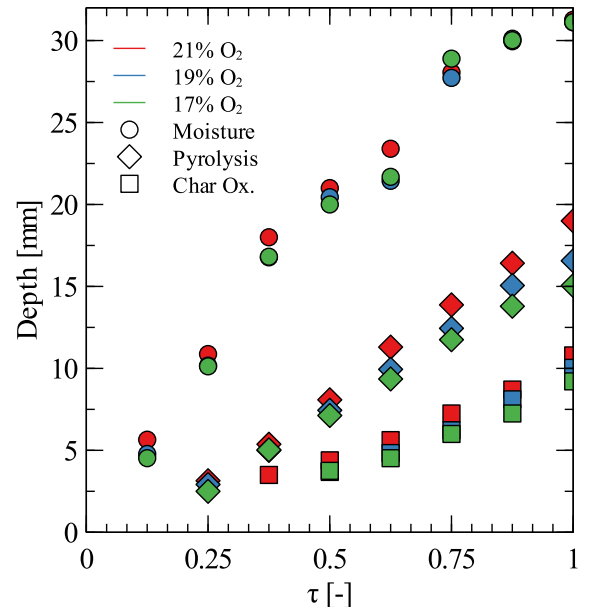

(b)

Figure 5: Normalized transient burning of timber. (a) MLR for different $\mathrm{O}_{2}$ concentrations. (b) Propagation of the different reaction fronts within the solid.

Finally, the decrease in the steady-state MLR achieved by the sample can be analysed by considering the scenario described by the different reaction fronts presented. As the $\mathrm{O}_{2}$ concentration decreases, the char oxidation reaction will be directly affected, slowing down its propagation. This will initially generate an increase in the char layer thickness. As the char layer increases, so does the amount of heat being retained by it. Furthermore, this increase in char layer thickness combined with the decrease in the amount of energy provided by both the flame and the char oxidation reaction will lead to a decrease in the amount of heat that reaches the pyrolysis front, affecting directly the thermal decomposition rate, or MLR of the sample.

\subsection{Self-extinction}

Following the methodology proposed in Section 3.2, once the samples have reached a thermal steady state and yield a worst-case scenario analysis, the incident heat flux over the exposed 
surface was decreased in order to determine the minimum set of conditions that allow to sustain flaming. The results of this stage are presented in Figure 6.

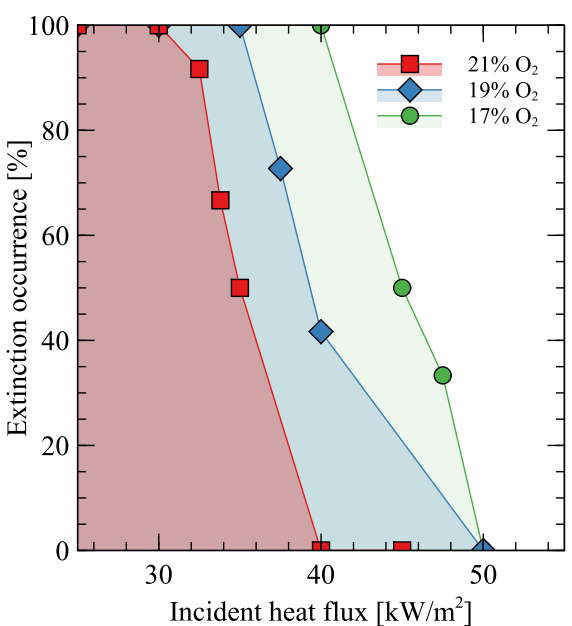

(a)

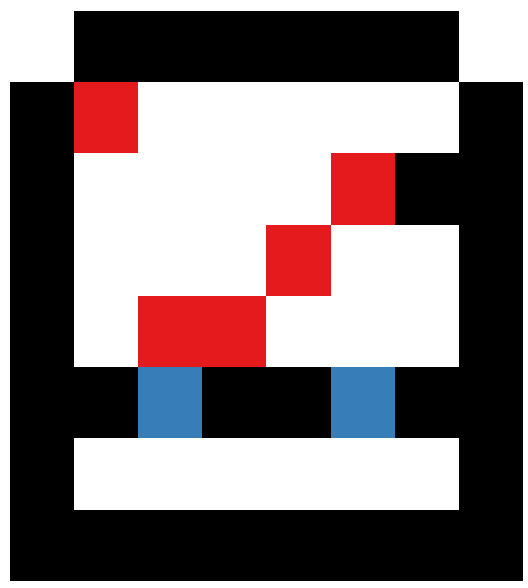

(b)

Figure 6: Critical conditions for the self-extinction of timber. (a) Occurrence of self-extinction for different secondary incident heat fluxes, under different $\mathrm{O}_{2}$ concentrations. (b) Influence of $\mathrm{O}_{2}$ concentration over the steadystate MLR and critical MLR for self-extinction of timber.

Figure 6(a) presents the number of times self-extinction occurred, as a percentage of the total amount of tests conducted at a given set of conditions $(12,6$ tests to measure mass loss, and 6 to perform in-depth temperature measurements). It is important to notice that the occurrence of selfextinction is not a binary phenomenon, but a probabilistic one, greatly affected by testing conditions, sample preparation, and most importantly, the inherent heterogeneity of the material. From the figure, it can be seen that for ambient air, a secondary incident heat flux of $30 \mathrm{~kW} / \mathrm{m}^{2}$ lead to the extinction of the 12 samples tested. As the heat flux was increased, the number of samples that self-extinguished decreased almost linearly. For a secondary incident heat flux of $40 \mathrm{~kW} / \mathrm{m}^{2}$, no samples self-extinguished when tested under an ambient atmosphere.

When the $\mathrm{O}_{2}$ concentration was decreased, the same behaviour was observed; the number of samples that extinguished decreased linearly while increasing the secondary incident heat flux until reaching a heat flux high enough to sustain flaming. Nevertheless, the critical values that bound this behaviour are found to increase as the $\mathrm{O}_{2}$ concentration decreases.

Figure 6(b) shows the variation on the MLR measured at extinction as well as the steady-state MLR achieved by the samples, as a function of the $\mathrm{O}_{2}$ concentration. As it can be seen, both parameters exhibit opposite behaviours; As previously discussed, decreasing the amount of $\mathrm{O}_{2}$ available decreases the amount of heat that reaches the pyrolysis front, therefore lowering the MLR. On the other hand, the MLR measured at extinction increases when the $\mathrm{O}_{2}$ available decreases. It is argued that this is due of the fact that a reduction in the amount of $\mathrm{O}_{2}$ available lowers the efficiency of the combustion process, causing a higher demand for fuel (and therefore a faster decomposition rate) to generate the amount of energy necessary to sustain the flame. 


\subsection{Burning behaviour under secondary heat flux}

Error! Reference source not found. shows the key findings of the effects of $\mathrm{O}_{2}$ concentration after incident heat flux was reduced. Error! Reference source not found.(a) shows the MLR observed for samples where sustained flame continued and samples for which extinction occurred; under identical conditions $\left(21 \% \mathrm{O}_{2}\right.$ concentration and an incident heat flux of $\left.33.8 \mathrm{~kW} / \mathrm{m}^{2}\right)$. This plot shows that for a timber sample that suffers extinction, MLR continues to steadily decrease. In this scenario, smouldering combustion is found to take place, and the different reaction fronts still propagate within the sample, but at a much slower rate. Furthermore, it was observed that the smouldering process was not self-sustained and halted briefly after the complete removal of heat at the exposed surface. For a timber sample where sustained flame was observed, the MLR reaches a new steady-state $\left(3.82 \pm 0.4 \mathrm{~g} / \mathrm{m}^{2} \mathrm{~s}\right)$. The presence of flame increases the amount of heat impinging over the surface of the sample, thus promoting the rate of char oxidation and increasing the amount of heat conducted into the pyrolysis front.

Error! Reference source not found.(b) shows the effect of $\mathrm{O}_{2}$ over the flaming combustion of timber, by comparing the MLR of samples tested under the same thermal exposure $\left(40 \mathrm{~kW} / \mathrm{m}^{2}\right)$, but under different atmospheres $\left(19 \%\right.$ and $21 \% \mathrm{O}_{2}$ concentration). Since in both scenarios sustained flaming was observed, this plot shows the influence of $\mathrm{O}_{2}$ concentration in the characteristics of the flame and the influence that this has in the solid. At a $21 \% \mathrm{O}_{2}$ concentration atmosphere, the samples reach a secondary steady-state MLR of $4.23 \pm 0.4 \mathrm{~g} / \mathrm{m}^{2} \mathrm{~s}$. When the $\mathrm{O}_{2}$ concentration is reduced to $19 \%$, the magnitude of the MLR stabilizes at a lower value of $3.83 \pm 0.5$ $\mathrm{g} / \mathrm{m}^{2} \mathrm{~s}$. As already discussed, a reduction in the amount of $\mathrm{O}_{2}$ available will decrease the heat flux from the flame to the exposed surface, the char oxidation rate, and the surface temperature, resulting in an overall decrease in the amount of heat conducted to the pyrolysis front, lowering the decomposition rate of the burning sample.

Error! Reference source not found.(c) shows the MLR for samples that extinguished when tested under the same thermal exposure $\left(40 \mathrm{~kW} / \mathrm{m}^{2}\right)$, but under different atmospheres $\left(17 \%\right.$ and $19 \% \mathrm{O}_{2}$ concentration). Since in both scenarios self-extinction occurred, this plot shows the influence of oxygen $\mathrm{O}_{2}$ in the rate of smouldering combustion taking place within the solid. As it can be seen, there is no significant impact of the concentration of $\mathrm{O}_{2}$ at the solid's surface over the propagation of this combustion regime. Furthermore, it can be said that for the different $\mathrm{O}_{2}$ concentrations presented, there might not be a great variation on the rates of char oxidation taking place at the surface.

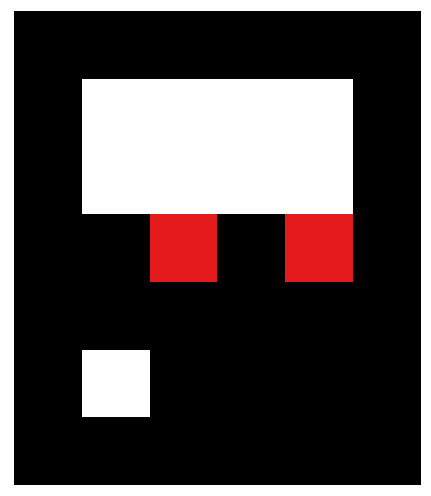

(a)

(b)
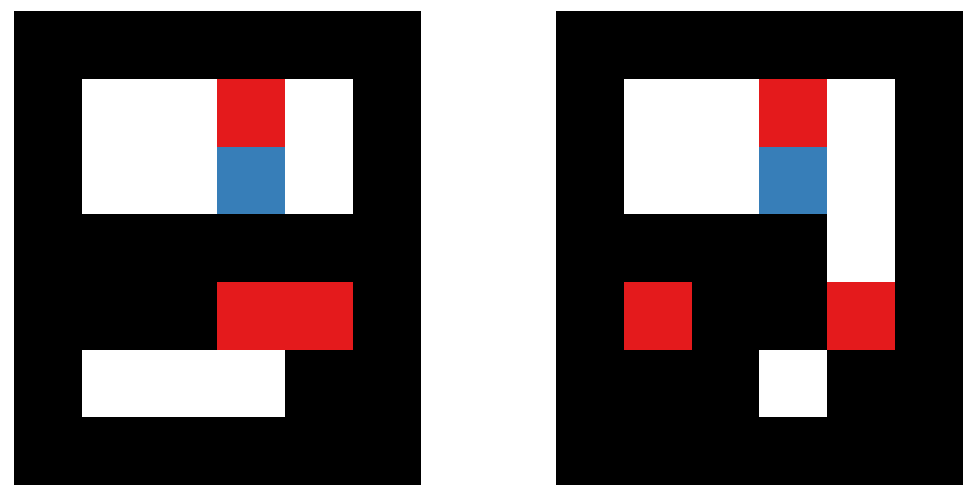

13 
Figure 7: Effect of $\mathrm{O}_{2}$ concentration after lowering the incident heat flux. (a) influence of the flame over the MLR.

(b) influence of $\mathrm{O}_{2}$ over the burning of timber. (c) influence of $\mathrm{O}_{2}$ after flame extinction.

\section{Conclusions}

The work described herein aimed at investigating the influence of the $\mathrm{O}_{2}$ concentration in the overall burning behaviour of timber: ignition, initial stage of transient burning, the moment of selfextinction, and late stage after extinction has occurred. Scenarios where self-extinction was observed where analysed and compared against scenarios where sustained flaming (therefore no self-extinction) was observed. The following key conclusions were found based on the outcomes of this work:

- The time to ignition of timber is increased by approximately $30 \%$ and $58 \%$ when the $\mathrm{O}_{2}$ concentration is reduced from normal conditions to $19 \%$ and $17 \%$, respectively.

- The MLR during transient burning shows a similar trend, regardless of the $\mathrm{O}_{2}$ concentration used. $\mathrm{O}_{2}$ concentration significantly influences the magnitude of the steady-state MLR: $5.09 \pm 0.5 \mathrm{~g} / \mathrm{m}^{2} \mathrm{~s}$ at $21 \% \mathrm{O}_{2}, 4.40 \pm 0.4 \mathrm{~g} / \mathrm{m}^{2} \mathrm{~s}$ at $21 \% \mathrm{O}_{2}$, and $3.91 \pm 0.6 \mathrm{~g} / \mathrm{m}^{2} \mathrm{~s}$ at $17 \% \mathrm{O}_{2}$. Oxygen concentration slightly influences the time to reach a steady-state MLR: $25 \mathrm{~min}$ at $21 \% \mathrm{O}_{2}, 22.5 \mathrm{~min}$ at $21 \% \mathrm{O}_{2}$, and $20 \mathrm{~min}$ at $17 \% \mathrm{O}_{2}$.

- Regardless of the $\mathrm{O}_{2}$ concentration, the occurrence of self-extinction is not a binary process that will always occur under a unique set of conditions. Out of the 12 repeat tests performed for each identical condition (oxygen concentration and incident heat flux). As previously stated, the authors have chosen this to approach to account for the uncertainty when performing bench-scale experiments in a material as intrinsically variable as timber.

- For samples tested for $21 \% \mathrm{O}_{2}$ concentration, self-extinction always occurs for an incident radiant heat flux of $30 \mathrm{~kW} / \mathrm{m}^{2}$ but never occurs for $40 \mathrm{~kW} / \mathrm{m}^{2}$; for heat fluxes in between this range, the occurrence of self-extinction has a variant occurrence.

- The above was also observed for $19 \% \mathrm{O}_{2}$ concentration, where self-extinction always occurs for an incident heat flux of $37.5 \mathrm{~kW} / \mathrm{m}^{2}$ but never occurs for $50 \mathrm{~kW} / \mathrm{m}^{2}$. And also, for $17 \%$ $\mathrm{O}_{2}$ concentration, where self-extinction always occurs for an incident heat flux of $45 \mathrm{~kW} / \mathrm{m}^{2}$ but never occurs for $50 \mathrm{~kW} / \mathrm{m}^{2}$.

- The $\mathrm{O}_{2}$ concentration influences the MLR upon self-extinction. At standard air conditions, a critical MLR of $3.65 \pm 0.4 \mathrm{~g} / \mathrm{m}^{2} \mathrm{~s}$ was identified, whereas $19 \%$ and $17 \%$ the value increases to $3.74 \pm 0.6 \mathrm{~g} / \mathrm{m}^{2} \mathrm{~s}$ and $3.83 \pm 0.7 \mathrm{~g} / \mathrm{m}^{2} \mathrm{~s}$, respectively.

\section{Acknowledgements}

The authors are grateful for the contribution of Mélina Drout-Battestini in this work. The authors would also like to acknowledge the support of CONICYT-Becas Chile (Grant No. 201672170283) and Australia Research Council Research Hub for Advanced Solutions to Transform Tall Timber Buildings (Grant No. IH150100030). 


\section{References}

[1] D. Barber, R. Gerard, Summary of the fire protection foundation report - fire safety challenges of tall wood buildings, Fire Sci. Rev. 4 (2015) 5. doi:10.1186/s40038-015-00093 .

[2] C. Lautenberger, C. Fernandez-Pello, A model for the oxidative pyrolysis of wood, Combust. Flame. 156 (2009) 1503-1513. doi:10.1016/j.combustflame.2009.04.001.

[3] Y. Utiskul, J.G. Quintiere, A.S. Rangwala, B.A. Ringwelski, K. Wakatsuki, T. Naruse, Compartment fire phenomena under limited ventilation, Fire Saf. J. 40 (2005) 367-390. doi:10.1016/j.firesaf.2005.02.002.

[4] M.A. Delichatsios, Piloted ignition times, critical heat fluxes and mass loss rates at reduced oxygen atmospheres, Fire Saf. J. 40 (2005) 197-212. doi:10.1016/j.firesaf.2004.11.005.

[5] C.H. Bamford, J. Crank, D.H. Malan, A.H. Wilson, The combustion of wood. Part I, Math. Proc. Cambridge Philos. Soc. 42 (1945) 166-182. doi:10.1017/S030500410002288X.

[6] A. Tewarson, R.F. Pion, Flammability of plastics-I. Burning intensity, Combust. Flame. 26 (1976) 85-103. doi:10.1016/0010-2180(76)90059-6.

[7] R. V. Petrella, The mass burning rate and mass transfer number of selected polymers, wood, and organic liquids, Polym. Plast. Technol. Eng. 13 (1979) 83-103. doi:10.1080/03602557908067676.

[8] R. Emberley, A. Inghelbrecht, Z. Yu, J.L. Torero, Self-extinction of timber, Proc. Combust. Inst. 36 (2017) 3055-3062. doi:10.1016/j.proci.2016.07.077.

[9] R. Emberley, T. Do, J. Yim, J.L. Torero, Critical heat flux and mass loss rate for extinction of flaming combustion of timber, Fire Saf. J. 91 (2017) 252-258. doi:10.1016/j.firesaf.2017.03.008.

[10] R. Crielaard, J.W. van de Kuilen, K. Terwel, G. Ravenshorst, P. Steenbakkers, Selfextinguishment of cross-laminated timber, Fire Saf. J. 105 (2019) 244-260. doi:10.1016/j.firesaf.2019.01.008.

[11] A. Bartlett, R. Hadden, L. Bisby, B. Lane, Auto-extinction of engineered timber: the application of firepoint theory, Interflam. (2016).

[12] T.J. Ohlemiller, T. Kashiwagi, K. Werner, Wood gasification at fire level heat fluxes, Combust. Flame. 69 (1987) 155-170. doi:10.1016/0010-2180(87)90028-9.

[13] C. Beyler, Unified model of fire suppression, J. Fire Prot. Eng. 4 (1992) 5-16. doi:10.1177/104239159200400102.

[14] Y. Xin, M.M. Khan, Flammability of combustible materials in reduced oxygen environment, Fire Saf. J. 42 (2007) 536-547. doi:10.1016/j.firesaf.2007.04.003.

[15] E. Mikkola, Charring Of Wood Based Materials, Fire Saf. Sci. 3 (1991) 547-556. doi:10.3801/IAFSS.FSS.3-547.

[16] T. Kashiwagi, T.J. Ohlemiller, K. Werner, Effects of external radiant flux and ambient 
oxygen concentration on nonflaming gasification rates and evolved products of white pine, Combust. Flame. 69 (1987) 331-345. doi:10.1016/0010-2180(87)90125-8.

[17] V. Babrauskas, Charring rate of wood as a tool for fire investigations, Fire Saf. J. 40 (2005) 528-554. doi:10.1016/J.FIRESAF.2005.05.006.

[18] F. Browne, Theories of the combustion of wood and its control, United States Dep. Agric. For. Serv. Rep. No. 2136. (1958) 1-72.

[19] M.J. Spearpoint, J.G. Quintiere, Predicting the burning of wood using an integral model, Combust. Flame. 123 (2000) 308-325. doi:10.1016/S0010-2180(00)00162-0.

[20] ASTM International, E2058-19 Standard Test Methods for Measurement of Material Flammability Using a Fire Propagation Apparatus (FPA), Astm. 44 (2019) 1-31. doi:10.1520/E2058-19.

[21] E.C. Beder, C.D. Bass, W.L. Shackleford, Transmissivity and Absorption of Fused Quartz Between $022 \mu$ and $35 \mu$ from Room Temperature to $1500^{\circ} \mathrm{C}$, Appl. Opt. 10 (1971) 2263 . doi:10.1364/AO.10.002263.

[22] M. Chaos, Spectral aspects of bench-scale flammability testing: Application to hardwood pyrolysis, Fire Saf. Sci. 11 (2014) 165-178. doi:10.3801/IAFSS.FSS.11-165.

[23] P. Reszka, J.L. Torero, In-depth temperature measurements in wood exposed to intense radiant energy, Exp. Therm. Fluid Sci. 32 (2008) 1405-1411. doi:10.1016/j.expthermflusci.2007.11.014.

[24] M.F. Modest, Radiative heat transfer Michael F. Modest., 3rd ed.., Academic Press, New York, 2013.

[25] J.I. Cuevas, J.P. Hidalgo, J.L. Torero, C. Maluk, Complexities of the thermal boundary conditions when testing timber using the fire propagation apparatus, Proc. Ninth Int. Semin. Fire Explos. Hazards. (2019) 959-969. doi:10.18720/spbpu/2/k19-88.

[26] N. Bal, J. Raynard, G. Rein, J.L. Torero, M. Försth, P. Boulet, G. Parent, Z. Acem, G. Linteris, Experimental study of radiative heat transfer in a translucent fuel sample exposed to different spectral sources, Int. J. Heat Mass Transf. 61 (2013) 742-748. doi:10.1016/j.ijheatmasstransfer.2013.02.017.

[27] P. Boulet, D. Brissinger, A. Collin, Z. Acem, G. Parent, On the influence of the sample absorptivity when studying the thermal degradation of materials, Materials (Basel). 8 (2015) 5398-5413. doi:10.3390/ma8085251. 


\section{Figure captions}

Figure 1: Burning of timber. (a) Energy balance at the char layer. (b) MLR of a burning timber element. Source [9].

Figure 2: Schematic of the FPA.

Figure 3: Incident heat flux over the target surface (normalized against the maximum value at the surface): (a) experimental results used as model validation, (b) modelled spatial distribution over the exposed surface, and (c) modelled spatial distribution over the complete sample.

Figure 4: Transient burning of timber. (a) Average MLR at $17 \% \mathrm{O}_{2}$. (b) Average MLR at 19\% $\mathrm{O}_{2}$. (c) Average MLR at $21 \% \mathrm{O}_{2}$. (d) Time to ignition as a function of $\mathrm{O}_{2}$ concentration.

Figure 5: Normalized transient burning of timber. (a) MLR for different O2 concentrations. (b) Propagation of the different reaction fronts within the solid.

Figure 6: Critical conditions for the self-extinction of timber. (a) Occurrence of self-extinction for different secondary incident heat fluxes, under different $\mathrm{O} 2$ concentrations. (b) Influence of $\mathrm{O} 2$ concentration over the steady-state MLR and critical MLR for self-extinction of timber.

Figure 7: Effect of O2 concentration after lowering the incident heat flux. (a) influence of the flame over the MLR. (b) influence of $\mathrm{O} 2$ over the burning of timber. (c) influence of O2after flame extinction. 